\title{
Publisher Correction: The agony of stereotyping holds Black women back
}

Ebony Omotola McGee

Correction to: Nature Human Behaviour https://doi.org/10.1038/s41562-020-01001-8, published online 16 November 2020.

In the version of this article initially published, the last two sentences were omitted. They should read, "And as the glass ceiling cracks with the historic election of the first woman - and critically the first Black woman-as the vice president of the United States, we will undoubtedly continue to grapple with stereotypes. However, the strength of 22 million Black women can pick up the pieces and begin again, to create an America that respects and protects Black women." The error has been corrected in the PDF and HTML versions of this article.

Published online: 24 November 2020

https://doi.org/10.1038/s41562-020-01015-2

๑ Springer Nature Limited 2020 